\title{
Article \\ Corporate Risk Tolerance and Acceptability towards Sustainable Energy Transition
}

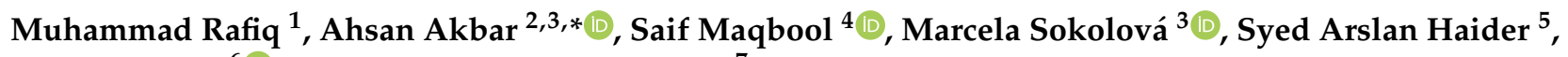 \\ Shumaila Naz ${ }^{6}$ and Syed Muhammad Danish ${ }^{7}$
}

check for

updates

Citation: Rafiq, M.; Akbar, A.;

Maqbool, S.; Sokolová, M.; Haider,

S.A.; Naz, S.; Danish, S.M. Corporate

Risk Tolerance and Acceptability

towards Sustainable Energy

Transition. Energies 2022, 15, 459.

https://doi.org/10.3390/en15020459

Academic Editors: Mirela Panait,

Daniel Balsalobre-Lorente,

Umer Shahzad, Abdul Rehman and

Magdalena Radulescu

Received: 25 November 2021

Accepted: 28 December 2021

Published: 10 January 2022

Publisher's Note: MDPI stays neutral with regard to jurisdictional claims in published maps and institutional affiliations.

Copyright: (c) 2022 by the authors. Licensee MDPI, Basel, Switzerland. This article is an open access article distributed under the terms and conditions of the Creative Commons Attribution (CC BY) license (https:// creativecommons.org/licenses/by/ $4.0 /)$.
1 Faculty of Management Sciences, Superior University, Lahore 54000, Pakistan; m.rafiq@superior.edu.pk

2 International Business School, Guangzhou City University of Technology, Guangzhou 510080, China

3 Department of Management, Faculty of Informatics and Management, University of Hradec Kralove, 50003 Hradec Kralove, Czech Republic; marcela.sokolova@uhk.cz

4 FAST School of Management, Chiniot-Faisalabad Campus, National University of Computer and Emerging Sciences, Chiniot 35400, Pakistan; saif.maqbool@nu.edu.pk

5 Department of Management, Sunway University Business School (SUBS), Sunway University, Bandar Sunway 47500, Malaysia; haidershah24@gmail.com

6 Faculty of Business Administration, Iqra University, Karachi 75500, Pakistan; shumaila.superior@gmail.com

7 Department of Security, Economics and Planning, Faculty of Science and Technology, University of Stavanger, 4021 Stavanger, Norway; danishhader060@gmail.com

* Correspondence: akbar@gcu.edu.cn

\begin{abstract}
The omnipresence of risk prevails in almost every aspect of human life. Individuals and societal factors are pivotal in the decision-making process to judge acceptability and tolerability of risk. Tolerability of risk (ToR) is characterized by dynamism pinned in the process of decision making that helps to gauge the society and individual's risk. The energy transition implies switching the energy system from fossil fuels or any traditional mechanism to modern renewable sources that are sustainable. The energy transition is paramount important in the current global energy system to attain sustainable goals for organizations. This study used the positivism research paradigm to address the research questions. The quantitative approach helps to examine the cause-and-effect relationship. It also helps to collect systematic information to meet the objectives of the research. A total sample of 300 was selected for the data collection from renewable energy companies. The study used positivism research philosophy applied deductive approach. The data is analyzed through PLS-SEM. It is summarized that the scale of risk acceptability and tolerability in Pakistan is moderate which encourages companies to work progressively and increases sociocultural activities to make society a partner of this new shift in energy transition that will ultimately increase the level of risk acceptability. Nevertheless, as a society, people are neither high-risk takers nor risk avoiders due to income constraints, macroeconomic uncertainty, and political instability.
\end{abstract}

Keywords: risk tolerability and acceptability; sustainable energy transition; renewable energy usage; Pakistan

\section{Introduction}

The organizations that do not forecast risk probability cannot stay longer due to stiff competition in the corporate world. Risk is an undeniable factor in business operations, but meanwhile it is also an imperative factor for organizational growth and development, especially in energy transition [1]. The omnipresent risk is prevailing in almost every activity of human beings. To decide whether the risk is unacceptable, tolerable, or acceptable, risk analysis is a fundamental activity established for this precedent. Individual and societal factors become essential and pivotal in the decision-making process at this stage to judge acceptability and tolerability of risk. The hazards potentially prevailing in societal activities associated with risk management remain a matter of sound public and technical interest. There is a considerable and continuous range of development in the 
context of the regulatory framework [2]. The establishment of many new frameworks of regulations is at its peak, except for the dearth in public debate on risk assessment at a general level, which needs remarkable extensions for an understanding of philosophical issues associated with tolerability and acceptability of risk especially related to sustainable energy transitions [3]. Changing the energy system is at the heart of public acceptability of risk towards the production of a more sustainable way of energy [4].

Viability of sustainable energy transition without tolerability and acceptability of risk through public change is merely possible. The planning process should be incorporated with a fundamental debate of risk acceptability and tolerability to avoid lateness and heavy losses in projects. Essentially, the policymakers, engineers and project managers should be profoundly knowledgeable about assessing the risks and its management [5]. Additionally, by going this way, the policymakers and engineers will safeguard the projects from misjudgment, the complexities associated with public activities, and solve the problems of risk acceptability. If the key concern of public interest around the energy project is failing, then such activities are counterproductive or even likely ineffective. A one-size-fits-all solution is not prevailing: as risk acceptability is dynamic hence, context, projects specificity, and parties linked matters most. The standard of judging for risk acceptability criteria is based on decisions related to risk acceptance during risk analysis and risk evaluation. Certainly, comparing the results of risk analysis with criteria of risk as a consequence of risk evaluation for the purpose to determine whether the level of risk is acceptable or tolerable or not. ALARP principle, absolute targets, GAME, etc. Are the different factors that guide to the distinction between acceptability and tolerability of risk? It also outlines the influencing factors for decision rules available to different industries, especially in the energy sector.

The original intended purpose is little beyond in once-built projects. The truncations are often found, but the potential rewards can be excellent [6]. On average it takes almost ten years to get good revenue, but the trajectory in the future is quite lucrative. The commitment of huge capitalization cost has to be carried out as a prior substantial upfront expenditure. The sponsorship from the state may work to reduce the trajectory of risk and may enhance the possibilities of coming up with perpetual success. Another way to hedge the risk and to ensure the long-lasting success can be attained through restructuring of debt and ownership to save prior investments. Managing risk is a real issue that can be minimized in this way.

The energy transition is getting attention due to global climate change, health issues, poverty, and dynamic needs of economics. It geared up after the United Nations millennium goals of sustainability and prosperity. The Initial cost of energy transition is high which is problematic for developing countries especially for Pakistan. The government of Pakistan has taken Initiative to give free solar lamps in schools and loans for solar panels to SMEs. Growth in the aging population, a change in labor markets, a change in shapes of human mobilization and urbanization, swift progress in technology and automation through information technology and extra societal movements, mega trends in technology and economy are shifting human job and life and business atmosphere by putting corporations under strong stress to write radically, the way of their operations [7-10]. Social performance of companies is growing parallel to bear unsustainable human and social activities that cause the exploitation of resources and to ignore inside and outside stakeholders of the organization [11].

Tolerability of risk (ToR) is characterized by dynamism that is pinned in the process of decision making that help to gauge the society and individual risk. The energy transition means changing the energy system from fossil fuel or any traditional mechanism to modern renewable sources that have a sustainable impact over another. A wide range of changes in economic and social activities demands high attention to transform the energy production from ancient and inefficient systems to a new and efficient system that can guarantee the minimum environmental depletion and maximum output. The energy transition is paramount important in the current global energy system for the purpose to gain sustain- 
able goals for organizations. The energy transition is defined in multiple ways. According to Hirsh and Jones [12] "A change in fuels (e.g., from wood to coal or coal to oil) and their associated technologies (e.g., From steam engines to internal combustion engines)". Tchiehe and Gauthier [2] explain energy transition as "The time that elapses between the introduction of a new primary energy source, or prime mover, and its rise to claiming a substantial share of the overall market".

The study is schemed as follows: the following chapter provides a literature review on risk acceptability and tolerability. The following chapter after the literature review is about research methodology and approach used by the research. The research methodology also supplements the information of data sampling and data collection techniques. The fourth chapter is about data analysis and interpretation to know the impact of risk acceptability and tolerability on energy transition. The last chapter is about discussion, conclusion and implications of the study.

\section{Literature Review}

\subsection{Risk Acceptability and Risk Tolerability}

The industrial risk management practices and policies' effectiveness are led by keener interest into an increased level of political maturity, development issues, and environmental awareness and higher education level increases social benefits. The risky and unfriendly policies of hazardous industries have increased public interest to take risks towards environmental protection. Despite this, 'risk' is perceived poorly as a concept with confusion between probability, something involving both probability and consequences, and something implying monetary or other loss. Vlek and Stallen [6] provided different concepts of risk or riskiness by combining or mixing all or components of the two main component ideas. The traditional decision analysis estimates the consequences of chance estimates for better risk analysis. The standard deviation of each estimate has a measure of uncertainty and social perception for better reflection of personal accuracy for risk acceptance and tolerance [13]. Regardless of all carefulness, there are chances of disagreement to prevail on an exact definition of risk acceptability and tolerability, as many psychological and sociological terms appear at risk, depending on the eventual outcome of one's stake and his point of view.

The level of risk acceptability or tolerability associated with any project or facility might depend on the group, society, or individual due to the complexity of issues prevailing in certain contexts on which situation is being drawn. It is nearly impossible to deal with the situation in one context with measures taken in another context with a certain situation and limitations. Furthermore, [14] suggested some useful critiques and summaries. Risk acceptability and tolerability are not necessarily the same, although it is an interchangeable term in many common risk analysis terms. In some situations, risk tolerability is referred to as readiness to live with risk to protect certain benefits and interests to manage it effectively. On the other hand, tolerance of risk means that we cannot ignore and neglect something, rather it is something we need to keep under review and try to minimize it. A lower level of risk criterion is associated with the concept of risk acceptability and additionally, acceptability means a more relaxed attitude towards risk. According to Thao and Van Tiep [4], the definition of 'acceptability' does not depict the disinclination that people that show hazardous activities in terms of nuclear power debate. The terms acceptability and tolerability must be distinct because it is important to understand and implement. The term acceptability means getting consent or acceptance towards regularity authorities for risky situation. On the other side the impact of the situation suggests that people have tolerability on the sad situation as they have shown their consent.

In most human activities, risks are omnipresent and get the attention of researchers to conduct studies for the purpose to comprehend and assess the risks involved in the activities. In fact, it is almost impossible to get rid of risks rather strategies can be driven to mitigate the risk(s) associated with a project. There is a plethora of studies conducted to generate a broad diversity of risks and concepts linked to the phenomena. In a broader 
view, the notion of risk permits researchers' efforts to put their energy and utilize capacities to avert and safeguard organizations and human beings from harmful activities whether it damage financially or sometimes damages natural resources [2]. Furthermore, according to standard Skitka, Bauman [15], the risk is uncertainty against loss of something that the organization aims to obtain, and risk lies on the elements that are beyond the control or are not fully controllable. Although risk has some limits, those limits are not well tacit, yet many methods and mechanisms of risk can help to analyze and access the quantum for decision making. These mechanisms and tools are effective to mitigate risk and making it acceptable and tolerable [4]. The term 'Risk acceptability' means the public or the organization is willing and can adhere to the potential loss on account of certain benefits that the risk is worth taking and is being under control. The studies show that the risk that is acceptable means it is tolerable [16].

Furthermore, the asserted acceptable risk refers to a tolerable risk as a subset. They asserted these concepts according to the contextual setting of society and the value system of a community. According to Haridasan and Kumar [17], the terms risk acceptability and risk tolerability are synonyms. On the other hand, some studies showed adversary concepts that tolerable risk does not mean accepting. Finlay and Fell [18] distinguished that tolerated risk can be lived with but without being fundamentally accepted also. The difference between the result of an event, their impact, and diversified interaction may be different than expectation is known as risk possibility. The risk is not only a descriptive term, but more possibility is to calculate risk in statistical terms while risk, uncertainty refers to a situation in which causal force and potential outcomes are not fully understood. The term risk is multi-faceted and needs to be unfolded for a clear understanding of driver, output, and cause. Regardless, the impact depends on how they are integrated and interacted and avoided to certain level. There is a wide range of risks associated with organizations that need to be consciously addressed, such as market risk, institutional risk, and financial risk.

Thus, locating a risk in the framework provides a guide as to what more, if anything, ought to be done as referred as risk control. It will inform the HSC or HSE's decisionmaking when considering risk regulation in general.

\subsubsection{Value Addition}

When the perceived value of the project has something positive and renewable projects and efficiency of technology in energy projects such as electric vehicles are more acceptable the symbolic possibility of accepting risk is higher. Public commitment and toward sustainable energy transition become a symbol of pride if they become part of renewable initiatives and they feel the excitement. For instance, in Japan, the wind turbines are named by the people who contributed to the wind park and they feel privileged in the community. The impeded potentially signals that the value of risk acceptability can be yielded by providing financial incentives and gives chances to earn money. At the heart of sustainable energy transition projects, there is an opportunity to reduce the risk by providing more values as an alternative to their risk acceptability.

Additionally, the striving of the people towards the general goals are motivated by value additions. Schwartz [19] also shows what is pivotal to common people in different situations and across time. To a certain extent, values are endorsed by people across the world, and they differently prioritize the values. It is important to label the term 'value' that refers to individual characteristics of evaluating the projects and estimating the perceived benefits out of that project. Different implications are seen in different energy projects for people's values. Precisely, the characteristics of decision-making process, the distribution of cost and benefits analysis, the nature and environment consequences, the possible hazards of health and safety, the quality and security of energy supply and type of technology used are all different characteristics of energy projects that have implications for people's value [20]. 


\subsubsection{Trust in Stakeholders}

Several technological options are combined and facilitated in the transformation of energy, especially in wind, photovoltaic, and grid technologies. In private investments, cost and flow of revenue for various stakeholders is the key issue to deal with because of large financial involvements. It is equally important to understand that physical characteristics of risk are detailed information of stakeholders' questions and concerns. Moreover, apprehensions, fears, hopes, and emotions of social consequences as well as likely the risk acceptance for economic and political responses and implication. To underline the importance of inclusion of public and stakeholders' groups, the focus should be on governance rather than on administration or government for handling risk process and resultantly on establishing public-private partnership participatory partnership.

As a context of the framework, the stakeholders are defined as the socially organized group that will be influenced by the output of the activity or event by the risk management options or risk originates to counter the real risk of the project. It is not enough to involve stakeholders only, but related groups such as the non-organized observing public, the nonorganized affected public, opinion leaders and cultural elites, and the media, all have their significant role in risk governance. The quality of the participation process is a resulting benefit from stakeholder and public involvement. It is merely not possible and sufficient to get all parties around the table and hope for the catharsis effect to come spontaneously. It is essentially important to consider other participating factors such as time, effort, and resources that need to handle the care and respect [21]. For the encouragement of various actors, the participation process should be designed in which stakeholders can contribute wherever they have the competency to improve the process and products' quality.

\subsubsection{Fairness}

The important factors that have an influence on the acceptance of the decision are trust and fairness [5]. Additionally, this study depicts that people consider a decision as fair when the trustworthiness of decision-maker is being ensured. In this situation, the risk management context is more likely to be accepted. Currently, however, a decision is threatened values if the fair procedure has limited value as suggested by previous research [15]. Hence, this research identifies that procedural fairness for important decisions is important for the acceptance decision in people's life. The environmental hazards can also be accepted by fairness as suggested by risk communication scholars. In the fiduciary approach, the decision-making process is confined to a group of patrons who are obliged to make the 'common good' the guiding principle of their action. This approach also aligns involvement of the affected public and public scrutiny. For the patron, the public can provide suggestions as input for the arguments that are allowed in the policy formulation process and negotiation. The faith competence is part of a system that relies on fairness involved in the decision process for risk acceptability. According to personal affiliations and national prestige, advisers are selected.

\subsubsection{Attitude towards Technologies}

Energy use has created numerous problems, especially relate to the environment and society that have spurred the growth of technologies in sustainable energy such as, hydrogen vehicles, carbon capture and storage, and windmills. The successful introduction of these technologies in society is crucial due to resistance to public acceptance of these technologies [22]. Sustainable energy technologies are facing hindrance in the implementation of these technologies due to public resistance [23], which hampers the achievement of societal and environmental important goals. It is pivotal for sustainable energy technologies to understand the main concepts of these terms that why individuals go for action in against or favor of these technologies. The way of adoption and implementation of these technologies should be communicated for better acceptance of these technologies and successful implications. 
The psychological factors of acceptance of these technologies are discussed in many studies, but most of these studies emphasized more on limited psychological factors rather than a complete framework that has a key set of factors involving in acceptance of these technologies. Although, technology acceptance and influencing factors should be discussed and psychological factors' understanding and communication of citizens and application of the technology. The use of technology and support of technology reflects the accepted behavior to enable or promote rather a resistance of use of technology for better understanding. Because of the environmental benefits, the proclaiming of technology is supported and expressed for usage and support of technology. The risk tolerance of technology is due to certain behaviors and usage of technology depending on the favors they get out of it. When people oppose technology but do not take action (tolerance), it is known as connivance [23].

\subsection{Sustainable Energy Transition}

For the essential purpose to preserve the climate and natural resources, energy transition is inevitable. For the success of energy transition projects, public acceptance is fundamental and unavoidable. The current system of energy, especially in the developing world is unsustainable and cannot meet the requirement of environmental safety rather contributing to climate hazards. The ecological system is undergoing more tragedies due to unstable and unsustainable mechanisms of the energy system [24]. A socio-technical power system needs a profound transition mechanism to reduce carbon emissions. Renewable energy is purely to meet the objective to replace the fossil energy. It is not an easy job to do rather a complex way of handling economic, social, and technological challenges to resolve it may have to handle structural problems that have serious concerns in the energy transition. Broad structural lock-ins have been developed with the passage of time as, as identified in the literature of energy innovation [25]. The incremental improvements are observed as an incentive of the hard work of researchers and new approaches and technologies are replaced with conventional technologies [26].

The co-evolutionary process is identified in the transition of socio-technical between actors and social groups Geels [27], yet understanding of public on energy transition is still under study. A long way of involving structural changes in production and distribution is known as energy transition. The greater prominence in niches and innovation at the micro level for the purpose to gain greater prominence in form of niches at a micro-level. The determinant of novel innovation and understanding with an institutionalized framework for existing practices to change the conventional regime of energy production. Beyond the direct influence of exogenous environment is because of social-technological landscapes. It consists of mega conventions that have extensive pressure on societies, such as global environmental policy and regulations on the market that have an influence on awareness of the environment and policymaking for energy resources or the availability of power resources. Moreover, the sustainable energy process is a long way to achieve through a systematic approach $[28,29]$.

The main challenges in socio-technological transitions are innovations in practices, new ideas, and emerging at the niche level to realize the dream of sustainable power transition. The organizational innovation process is underpinned in niche-regime. The number of successful innovations normally challenge the dominant regime, in this way the new dominant regime evolves and helps energy transition projects [30]. For innovation in the energy transition, the most important and key element is the use of technology to get cleaner energy [31,32]. The participation of social and citizens support is helpful for a socio-technological transition that increases the understanding of public awareness and decreases levels of risk. The study is eventually helpful because we take samples of participants from the local community of Pakistan to know what their approach toward energy transition is and how they look at the future of energy transition. It is also important to mention that this study links energy transition with different approaches of risk taking to understand the phenomena of risk acceptability and tolerability. The reason of selecting 
Pakistan is due to expanding market and rapidly growing market due to which energy consumption demand is also rapidly growing. As a matter of fact, the decisions related to energy are influenced by national policies, consumption by companies and consumers. It also gets some influence from the international market, especially from the Chinese market due to long-lasting contracts with Chinese power corporations.

\subsubsection{Potential Positive Effects}

From a clean, renewable source, the local governments can drastically minimize their footprints of carbon by dealing with a contract of carbon emission trade. Local governments lead by example through purchasing renewable energy, purchasing green power, or by generating energy on-site. Where renewable resources vary in quality and availability there, governments can use a combination of renewable energy options in some regions to meet the local requirements of energy. Renewable energy transformation has laid the foundations of sustainable energy form in the electric power sector as a key measure to prevent climate change and scarce resources depletion [33,34]. Until 2050, the German federal government has plans to produce $80 \%$ of electricity from renewable sources in the country [35]. The fundamental structure of an electrical system in the country will be affected and reshaped due to the transition from fossil fuel. The sustainable energy system will fundamentally change the way how power is sold, produced, and transmitted to industries and households [36-39]. Electricity generation was exclusively considered as the sphere of utilities, until some years ago. Due to the expansion of renewable energies, this trend has been dramatically changed. Until the end of 2012,23\% of electricity was produced from renewable energy sources in Germany [35]. Moreover, twelve percent of German utilities are operated and owned by the capacity of renewable energy resources [40].

According to the finding of different scholars, new core technology adoptions are required to industry incumbents with technological innovations for better performance and potentially positive effects [41]. Solar energy, biomass, and wind power have changed electricity generation sources from fossil fuels and nuclear to renewable to mitigate environmental threats. O'Reilly 3rd and Tushman [42] define ambidexterity as a cerebral harmonizing act for administrators between upholding the present central commercial and emerging fundamentally new products and services for the future of the company. For new technologies and markets, the senior administration should be ready to configure future success with solid assets, without compromising the effects on established businesses and keep them going well. The ambidexterity theory of organization is to assist and understand the utility challenges faced by renewable energies. This is named as renewable energy utilities business model.

Several recent studies have raised the issues of renewable energy business model in recent studies $[37,43,44]$. With an own underpinning business logic, two generic business models are pointed out in the literature; renewable energy business model utility-side and customer-side renewable energy business models. A capacity of one and some hundred megawatts are discussed in large-scale projects in the renewable energy business model of the utility-side. The main technologies of this application are large-scale solar thermal energy, biogas plants and biomass, large-scale photovoltaic systems, on and offshore wind energy, and concentrated solar power. Bulk generation of electricity is the value proposition of this business model [45]. Hence, the following hypothesis is postulated:

Hypothesis (H1). Potential positive effects of energy transition significantly influence risk acceptability.

The conventional electricity value chain is utilized in the electricity is fed into the grid and delivered to the customer. It is further discussed that less generation capacity than nuclear power plants and conventional coal power plants are also characterized in this business model and customer interference in these power purchase agreements is very low. 


\subsubsection{Effective Measures}

The reason that is pushing the world to switch on the sustainable energy system is underpinned by scarce petroleum supplies and facing global climate change. That historical energy transition is not sudden, rather these shifts occurred over a century or longer and was motivated by the scarcity of natural resources, technology innovation, and increase in labor cost. More rapidness is needed in the 21st century in energy transition. Sadly, the acceleration of the energy transition is little known. Thus, this study is pivotal to review the past studies on energy transitions and elements along with factors and measures. The ups and downs in these studies are evidence that much is done and more is needed to be done. The study in Brazil on shifting transport from oil-based to sugarcane ethanol got successful and was implemented with the full support of the local community. Moreover, the experiment of France for shifting electricity from oil to nuclear power was also successful, while the US faced the failure of mixing foreign oil with domestic energy resources. Resultantly, all these factors have lessons to learn in either case. The discussion on these lessons is important to take actions. The identification of several instruments and policy recommendations was accelerated in the energy transition despite the overall global energy transition circumstances are very slow due to different social and economic factors. The yield of timely results and new treaties are need of giving time to implement the programs in different countries with the promotion of Smart Grids, a greater focus on energy efficiency, and with different political economies.

Although the world is confronting an extraordinary urgency for a rapid energy transition to renewable and sustainable sources of energy, it is unlikely to happen in decades. In fact, critical energy transition is possible through stronger government commitments, and for policymakers, it is important to understand and realize the current energy policies and existing energy efficiency in technologies that are rapidly needed to implement and address the institutional barriers to recognize. Moreover, it is important to address and overcome the barriers for better measures [46]. The implementation and measurement of renewable energy and efficiency are rapid due to the existence of technologies and their cost-effectiveness. More energy can be saved in the electric power sector due to effective measures to minimize greenhouse gas emission than conservation technology in buildings and electric vehicles using hybrid electric gasoline. The recovery at larger quantities of waste heat is possible in the growing electric power sector due to electric power measures [47]. The following hypothesis is derived from above literature:

Hypothesis (H2). Effective measures of energy transitions significantly influences risk acceptability.

To reduce the impacts of environmental vulnerability, it is important to improve operating efficiency, enable the latest technology, digitalize the smart grid and improve and utilize the latest electric systems that can overlay information and technologies in communication for evolving global future vision of energy transition measures. Low power energy sensor technologies, electric meters with two-way communication features, and software to manage energy [48]. The definition and usage of a smart grid are still at an early stage of development and needs broader consensus more specific in definition and scope. Measures like the energy service model will increase customer satisfaction and will integrate energy efficiency technologies [48]. In the US, a 5\% power grid efficiency increase will save equivalent energy and will help to eliminate the greenhouse gasses of 53 million cars [49].

\subsubsection{Government Support}

The government is a key stakeholder in energy transition that can affect the performance of energy companies in either way. The decision regarding public support is taken by the government to offer clean energy. The policies are defined in light of public support that deploys clean energy and gives incentives to companies and individuals. In 
industrialized countries, the energy transition has become a prominent political question of sustainable energy due to rising concerns about energy security and environmental sustainability. Past studies have suggested that external shocks for understanding transitions are central and positive reinforcement [50]. National politics is affected in variegated ways due to international pressure as revealed in domestic literature of energy transition [51], impede sustainable energy transition and political strategies are in dearth in these theories and do not offer insights into related concepts. In the study, with support of quantitative evidence, I have tried to bridge the gap and presented the formal theory of sustainable energy transition.

Global de-carbonization is required to mitigate climate change, but without the improvement of technology, the cost of achieving emission reduction is high [52]. Without intervenes of the government, a sustainable energy transition is nearly impossible in a community as, the government helps to impose binding constraints on emissions of carbon either through using a price instrument or direct regulation [53]. Hence, fundamentally political factors are seen in sustainable energy transition. Strategically exogenous shocks in terms of oil price shocks are motives to get governments react. The extant literature suggests political constraints and constituency pressure [54,55], this is theoretically untreated. Although due to international pressure, strategic interactions are significantly in sighted on domestic responses [51,56,57].

Hypothesis (H3). Government support for energy transition significantly influences risk acceptability.

In fiscal management, some strategic considerations and political economists have been explored [58], but clean energy policy extent is questionable in these findings [59-61].

\subsubsection{Barriers to Energy Transition}

The embeddedness of energy system is fortified in the earth system, social system and economic system. It is absolute that the energy-economy or energy transition cannot exist as a standalone. The complexities in the system are not allowing the industry to progress according to the demand of the market, due to which the potential is not being optimized [62]. The economic and social systems are becoming the real complexities in setting up the modeling paramount in energy transition road map to gauge the proper assessment for implementation [63]. The change in climate is becoming the reason of these shifts in the energy system because it has deeper impact on the community and the economy that is dependent on this system of energy transition. A set of opportunities and challenges are risen as trigger of this response. By studying the enabler structural and environmental organisms, this system will assist in increasing the potential paybacks and eventually will lead to more information and reduction in barriers and will help the adjustments that are needed by along the way.

Technical issues are another barrier to this system that got the attention of many researchers is since the beginning of the 21st century. Since the start of this revolutionary century, renewable energy has got significant support by researchers and scientists [64]. The process to bring people from non-renewable sources to renewable sources is quite slow despite of the fat that scientists are coming up with convincing and practical technologies on renewable energy sources, this problem is much deeper in developing countries and is uncertain to some extent. Hence, this study is important to investigate the barriers, especially related to technologies and behavior of people towards the adoption of this factor. The use of energy is unarguable in rural and urban areas while production of this energy of coal is being discouraged in major part of the world [65]. Despite that fact, energy is still produced by mixed fossil fuels that are causing severe damage to the atmosphere [66].

Hypothesis (H4). Barriers to energy transition significantly influences risk acceptability. 


\section{Research Design}

This research study used the positivism research paradigm to rightly answer the research questions. It is suggested that when the research problem is empirical, then it is appropriate to use the positivism research paradigm. To determine the impact of the sustainable energy transition on risk acceptability and tolerability, a quantitative research approach was used in line with the positivism paradigm. The formal way of inquiry to achieve objective-oriented and systematic information is possible through a quantitative research approach that trials the realities quantitatively to determine the cause and effect link grounded upon assumptions of determination [67]. The study incorporated crosssectional design to collect data within a specific period from different respondents in one go. The choice is a rationale, according to the quantitative research approach besides its measuring limitation in phenomenon [67].

The universe unit considered for research is known as the population of the research [67]. Probability sampling techniques are used when data are collected through survey method adopted by quantitative research method [67]. Two Chinese power companies were selected as a case study while making sure their active participation in the energy transition. (1) China National Electric Engineering Company-CNEEC Pakistan, that company is actively working in Pakistan since 2012 on solar and wind forms of energy. (2) China power hub generation company (CPHGC). The rationale for selecting two energy companies as the sample is underpinned by the reason of the Pandemic situation around the globe and due to the inaccessibility of respondents. Additionally, the reason to select these companies is due to the aggressive participation of these companies in energy transition in Pakistan. The sample size is calculated through Rao-soft software which suggests the sufficiency of respondents. According to this formula, the desired sample size of 300 respondents was selected for an investigation to conduct the study. The data collection of the whole census was expensive, time demanding, and human resource intensive as well. This decision of collecting data from a selected sample is rationalized by different scholars and statisticians without compromising on the efficiency of results while being cost and time-efficient rather approaching the whole population.

\section{Measures}

A five-point Likert scale questionnaire was adapted from previous study [68]. The questionnaire has three major parts; the first part was consisting of basic information of respondents, such as age, gender, experience, etc. The second part was related to energy transition and the last part was comprised of risk acceptability and tolerability. The main variables were further categorized into different constructs to dig deeper into the research problem. For investigation purposes, the data used a primary source for its collection because the primary data source meets reliability and validity issues of data. The underlying associations can be grounded in the quantitative nature of data for exploring reality objectively. In this nature of data, the researchers test existing variables for generalizability of theories to check associations among variables that meet the objectives of this research. Aligned to the justification of data collection, the study is following positivism paradigm that focuses on scale development to minimize the biased elements prevails highly in the qualitative approach. Henseler and Ringle [69] assert that the survey method is the best approach to avoid biases and to generate results on a larger scale with a maximum possibility of accuracy.

Apart from the numerous benefits associated with survey strategy, certain reliability and validity issues are mandatory to be addressed while data collection and assessment. The solution to these concerns enhances the acceptability of research and makes it qualityoriented. It is worth mentioning here that the instrument is adapted from previous studies, as discussed above, which enhances the confidence in data instrument. Moreover, a pilot study of fifty respondents was carried to contextualize the instrument and to remove the possible reliability and validity issues. The experts' opinions and literature support were made to check the content and face validity of the instrument. Additionally, Cronbach's 
alpha helped to check the inter-item reliability, and all items' values were found reliable with a minimum acceptable value greater than 0.70 [70].

\section{Results and Discussions}

This chapter describes results and data analysis. To draw the results, descriptive and inferential statistics were applied. The descriptive analysis helped to summarize the demographics of the respondents, while inferential statistics helped to analyze the relationship between variables. The assumptions of regressions were analyzed through factor analysis to reduce the factors and eliminate the unloading factors. The reliability and validity of data were checked by Cronbach's Alpha and discriminant validity.

This study investigates the understanding of the impact of the sustainable energy transition on risk acceptability and tolerability. In this perspective, the study investigated the energies companies working in Pakistan that are using a sustainable energy transition model to measure the risk acceptability and tolerability. Additionally, the study took help of Chinese power corporations operating in Pakistan under the China-Pakistan Economic corridor (CPEC) one of the major projects of the Belt and Road Initiative (BRI) of China. To observe the relationship between independent and dependent variables data is collected from 300 respondents. The data is analyzed in Smart-PLS, the latest software to analyze the quantitative data and to test the hypothesis. SMART-PLS gives more insight to data and is more powerful data modeling software as compare to other software like SPSS. PLS also helps to create path models and gives more sophisticated look of research models. Mainly descriptive and inferential statistical analysis is used to infer the result to draw the results. The Figure 1 is the pictorial view of the research framework. It indicates that the sustainable energy transition is a dependent variable. To measure the dependent variable the study incorporated four elements to measure it with a maximum domain. Risk acceptability and tolerability is a dependent variable and is measured in different domain. The domains of measuring risk acceptability and tolerability are consisting of values addition, trust in stakeholders, fairness, and attitude towards technologies.

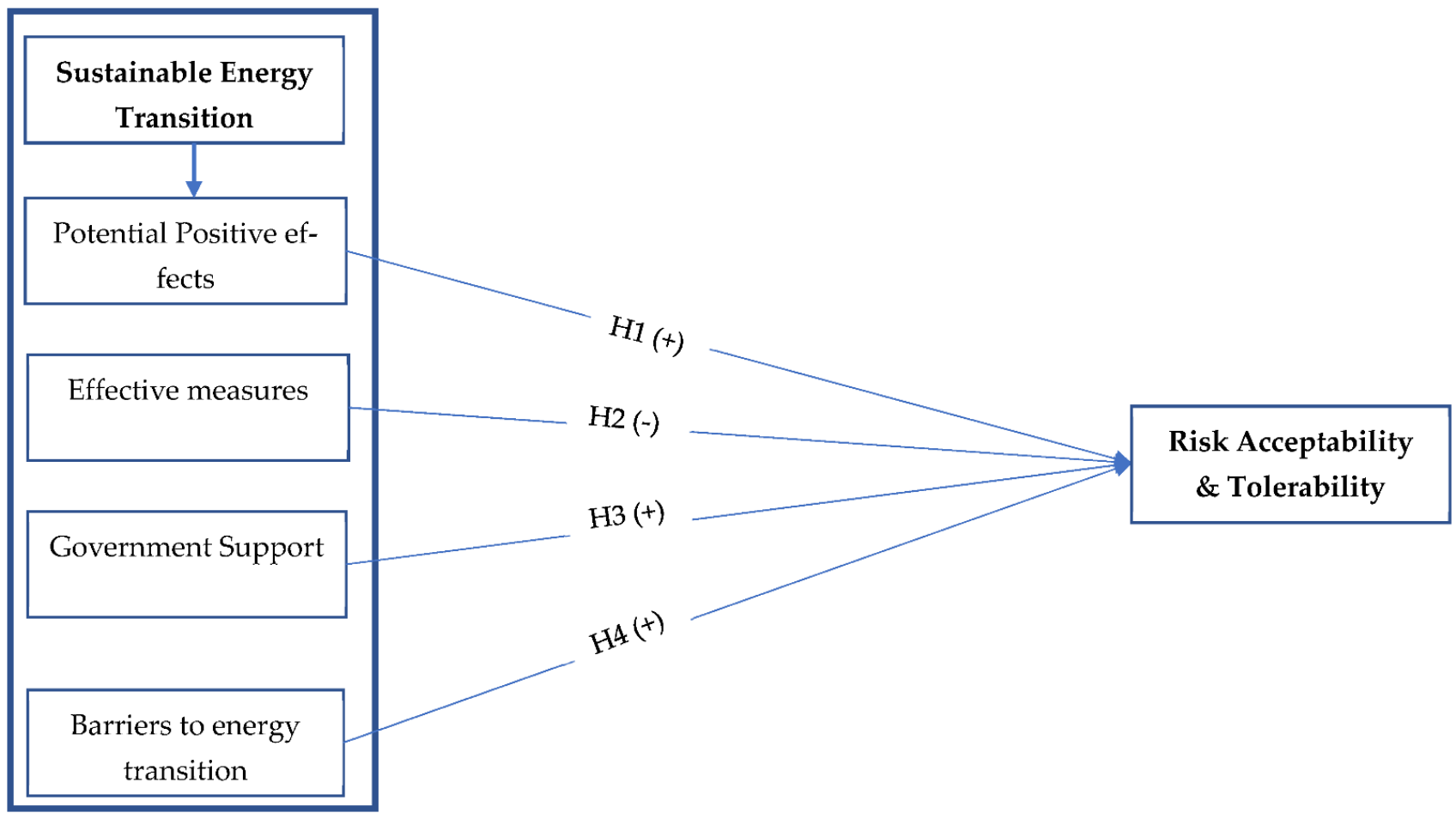

Figure 1. Research Model. 


\subsection{Demographic Analysis}

Demographical analysis can help researchers draw results about the demographics of respondents. Eventually, it is meaningful for understanding the gist of the sample used for the study. The following table indicates the major demographics used for the research. It shows that the contribution of male participants was dominant with a percentage of 72.8 followed by female respondents with $22.3 \%$. Age is another important demographical item presented in the table. The data of the table depicts that $24.9 \%$ of contributors in the research were 31-35 years bracket. It indicates that most of the respondents were youngsters who contributed in the study.

The next highest age bracket was from 36-40 with $23 \%$. The lowest percentage of respondents with the youngest age was from 20-25. Moreover, the designation of the respondents was important to measure to know about the decision-making ability of the respondents. The results indicate that majority of the respondents were from middle level of management which is an important layer in the management hierarchy to bridge the gap between higher and lower management. The last item in demographic was experience. The percentages in the table imply that majority of the respondents were with 5-7 years of experience with an accumulative $37.5 \%$ percentage. The lowest percentage in experience brace was $14 \%$. The detail is attached in Table 1.

Table 1. Demographics.

\begin{tabular}{llll}
\hline Items & & Frequency & Percent \\
\hline \multirow{3}{*}{ Gender } & Male & 222 & 72.8 \\
& Female & 68 & 22.3 \\
& $20-25$ & 14 & 4.6 \\
Age & $26-30$ & 25 & 8.2 \\
& $31-35$ & 76 & 24.9 \\
& $36-40$ & 70 & 23 \\
& $41-45$ & 62 & 20.3 \\
Designation & $46-50$ & 32 & 10.5 \\
& Above 50 & 17 & 5.6 \\
& Upper level & 18 & 5.9 \\
Experience & Middle level & 209 & 68.5 \\
& Operational level & 69 & 22.6 \\
& Less than 2 years & 44 & 14.7 \\
& Between 2 and 4 years & 84 & 27.5 \\
& Between 5 and 7 years & 109 & 35.7 \\
\hline
\end{tabular}

\subsection{Reliability}

It is pivotal for scientific research to critically address the issues of reliability and validity of data. Hence, the study also has rigorous approach to address this challenge. The following table indicates few valid tests suggested by different researchers to approve the reliability and validity measures of the data and instrument of the study. Cronbach's Alpha is considered among most used test to check the reliability of data. According to Tavakol and Dennick [71], the values of each variable should be above 0.70 to consider it reliable. So, it is obvious from the statistical analysis that all values of variables are above the minimum recommended value. 'Potential effects of energy transition' has highest values of Cronbach's Alpha while, 'Barriers to energy transition' is with lowest value 0.770 which is eventually greater than the accepted value. Composite reliability (CR) is another analysis that validates the reliability concerns of the data. The minimum accepted value of $\mathrm{CR}$ is 0.70 . So, all the values in this study are greater than 0.70 . The maximum value of CR in this study is 0.924 and minimum value is 0.843. According to Alarcón and Sánchez [72] the minimum accepted value of Average Variance Extracted (AVE) is 0.50. If the values of AVE are less than 0.50 it shows that data is not reliable. Hence, all the values of this study 
are above the accepted value range of AVE. the maximum value of AVE of this study is 0.673 and minimum value is 0.574 . The details are presented in Table 2 .

Table 2. Reliability analysis.

\begin{tabular}{llll}
\hline Variables & $\begin{array}{l}\text { Cronbach's } \\
\text { Alpha }\end{array}$ & $\begin{array}{l}\text { Composite } \\
\text { Reliability }\end{array}$ & $\begin{array}{l}\text { Average Variance } \\
\text { Extracted (AVE) }\end{array}$ \\
\hline Barriers to Energy transition & 0.770 & 0.843 & 0.574 \\
Effective Measures & 0.870 & 0.906 & 0.657 \\
Government support & 0.861 & 0.891 & 0.508 \\
Risk acceptability and tolerability & 0.892 & 0.915 & 0.577 \\
potential effects of energy transition & 0.898 & 0.924 & 0.673 \\
\hline
\end{tabular}

\subsection{Discriminant Validity}

Primarily, cross-loading examination and Fornel-Larcker criterion was applied to measure the discriminant validity [69]. The discriminant validity, conversely, cannot effectively be measured through the Fornel-Larcker method. Therefore, a multitrait-multimethod matrix was also used alternatively to measure discriminant validity for this research. The study also used the Heterotrait-monotrait correlation ratio to get the desired results. Henseler and Ringle [69] claim the value of heterotrait-monotrait ratio must be less than 0.85 to ensure the discriminant validity. The following table reports no issue of discriminant reliability as all values are under the accepted values range. All values in this table are below 0.85 . It is helpful to calculate and access measurement errors. It is used to correct the attenuation which helps to determine whether the concepts are related or unrelated. The details are attached in Table 3.

Table 3. Discriminant validity.

\begin{tabular}{llllll}
\hline & $\begin{array}{l}\text { Barriers to Energy } \\
\text { Transition }\end{array}$ & $\begin{array}{l}\text { Effective } \\
\text { Measures }\end{array}$ & $\begin{array}{l}\text { Government } \\
\text { Support }\end{array}$ & $\begin{array}{l}\text { Risk } \\
\text { Acceptability } \\
\text { and Tolerability }\end{array}$ & $\begin{array}{l}\text { Potential Effects } \\
\text { of Energy } \\
\text { Transition }\end{array}$ \\
\hline Barriers to Energy transition & 0.758 & - & - & - & - \\
Effective Measures & 0.424 & 0.811 & - & - & - \\
Government support & 0.513 & 0.770 & 0.713 & - & - \\
Risk acceptability and tolerability & 0.524 & 0.670 & 0.758 & 0.760 & - \\
potential effects of energy transition & 0.460 & 0.812 & 0.783 & 0.773 & 0.821 \\
\hline
\end{tabular}

\subsection{Factor Loadings}

Factor loading is important to test the research model. The purpose of factor loading is to condense many latent variables into smaller ones. The minimum accepted value in factor loading must be greater than or equal to 0.50 . If the values are less than the accepted value, the researchers eliminate those items. Twenty percent of total items can be deleted or skipped according to earlier studies [69]. After a careful process of factors examination, two items were deleted as those values were less than the recommended values. Pte1 and rat6 items were eliminated according to the principle. The following Figure 2, shows a pictorial view of factor loading according to the research model. 


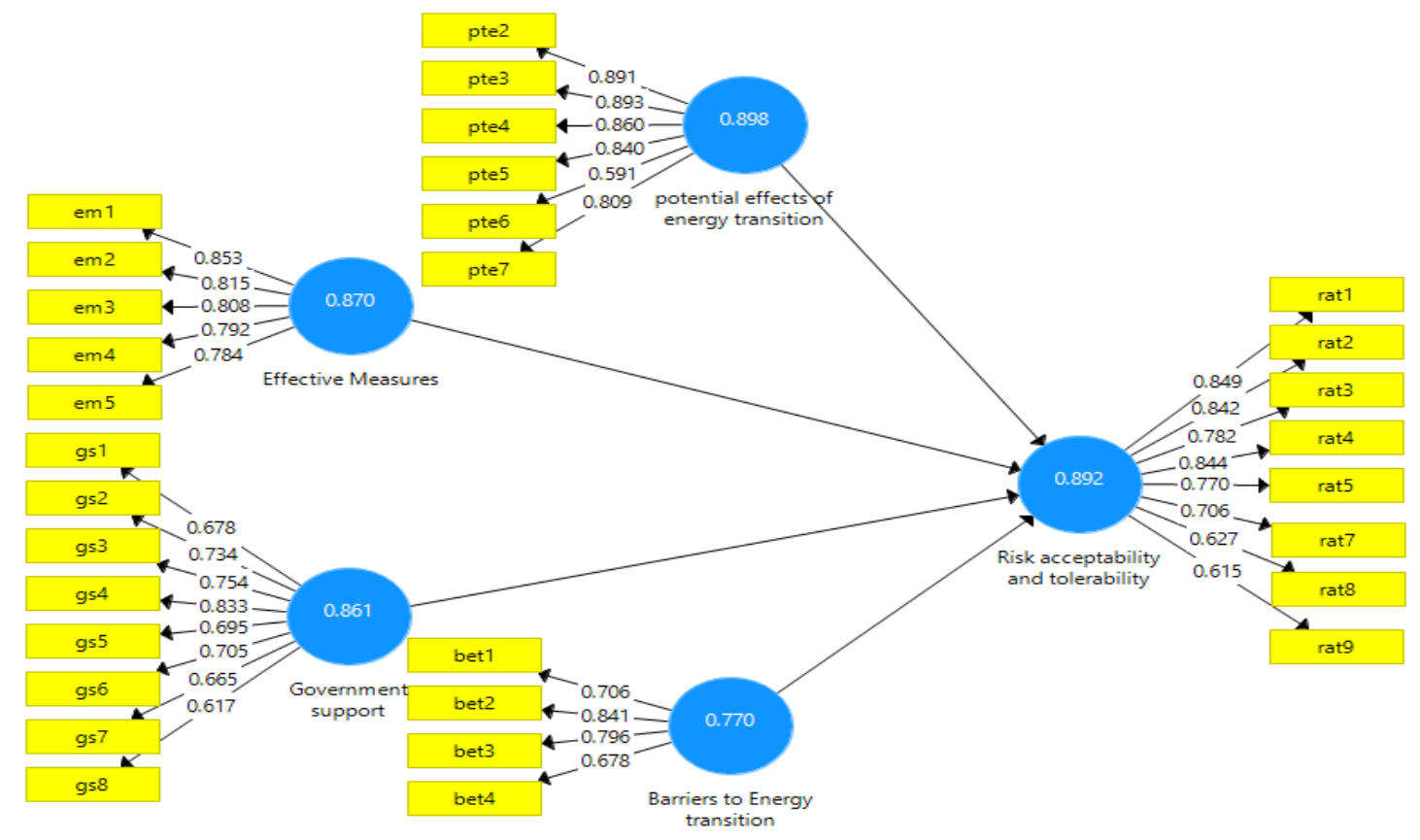

Figure 2. Factor Loadings.

\subsection{Regression Analysis}

Regression analysis is used to predict the assumptions. It tells us about an impact of independent variable on dependent variable. $\mathrm{R} 2$ is the value that shows the change in percentage due to independent variable in dependent variable. The increase in value of R2 means increase in effect of dependent variable. Sig/p-values indicates whether the relationship between variables exists or not. The study used multiple regression that is being used only when there are two or more than two independent variables.

The $\mathrm{R} 2$ values in the Table 4 indicate that the most effects are transferred in risk acceptability and tolerability through potential effects of the energy transition with the highest value of 0.351 while the lowest effect is transferred through effective measure with 0.126 in the dependent variable. Furthermore, it is also indicated in the Table 4 that all variables have a significant relationship with accepted values greater than 0.05 except effective measure with risk acceptability and tolerability. It means that there is no relationship between the effective measure and risk tolerability and acceptability.

Table 4. Regression analysis.

\begin{tabular}{|c|c|c|c|c|c|}
\hline Hypothesis & Relationship & f-Square & R-Square & T-Values & $\mathrm{Sig} / p$-Values \\
\hline $\mathrm{H} 1$ & $\begin{array}{l}\text { Barriers to Energy transition -> Risk } \\
\text { acceptability and tolerability }\end{array}$ & 0.050 & 0.238 & 3.611 & 0.000 \\
\hline $\mathrm{H} 2$ & $\begin{array}{l}\text { Effective Measures -> Risk acceptability } \\
\text { and tolerability }\end{array}$ & 0.001 & 0.126 & 0.504 & 0.614 \\
\hline $\mathrm{H} 3$ & $\begin{array}{l}\text { Government support -> Risk } \\
\text { acceptability and tolerability }\end{array}$ & 0.115 & 0.269 & 5.823 & 0.000 \\
\hline $\mathrm{H} 4$ & $\begin{array}{l}\text { potential effects of energy transition -> } \\
\text { Risk acceptability and tolerability }\end{array}$ & 0.178 & 0.351 & 6.870 & 0.000 \\
\hline
\end{tabular}

The Table 5 illustrates that hypothesis two is rejected as its value is above the significant value of 0.05 hence it is not supported according to statistical values. All other hypothesis is supported as the $p$-values are less than 0.05 . Hence, it is assumed that there is a significant relationship between variables other than effective measure and risk acceptability and tolerability. 
Table 5. Results of Hypotheses.

\begin{tabular}{lll}
\hline No. & Hypothesis & Status \\
\hline H1 & Barriers to Energy transition -> Risk acceptability and tolerability & Supported \\
H2 & Effective Measures -> Risk acceptability and tolerability & Rejected \\
H3 & Government support $->$ Risk acceptability and tolerability & Supported \\
H4 & potential effects of energy transition $->$ Risk acceptability and tolerability & Supported \\
\hline
\end{tabular}

\section{Discussion}

The results of this research indicate that the people in Pakistan are predictive in terms of risk-taking and risk acceptability. When they are asked whether or not they are willing to take risk, the findings reveal that $84 \%$ of the participants mentioned their support in favor of taking the risk. On the other hand, the support of the government was taken as a positive edge by the participants because it is a pivotal element that can affect the risk acceptability and tolerability in either way, but the participants encouraged the factor of the positive role of government by providing financial and governance support to hedge the risk. According to the findings, if the government provides technical and regulatory support to organizations, the organizations can make their plans and policies for the long term. Furthermore, it is also evident that measures of organizations can make organizations stronger to fight against unexpected circumstances by readily available backup plans. The societal impact on risk acceptability in terms of Pakistani culture is moderate as people conceive this new technology as a source of unemployment. Due to that reason, a few numbers of people are not in favor of taking risks, but the majority of the participants perceived it positive move for the benefit of society at large. In this regard acceptability of risk become vivid and it gives positive signs to the organizations. The risk acceptability and tolerability are also affected by barriers to the sustainable energy transition. The main problems that cause an energy transition to be risk-oriented is the behavior of people and avoidance of technology. The people of society are technophobes, due to which companies sometimes feel operations are risky and are unmotivated. Another factor that contributed to the measurement of risk acceptability and tolerability was the potential effects of the energy transition. Any project will be considered risky if it is not yielding profit to the organization. In this regard, the companies are found profitable and sustained due to a huge potential in the market. In fact, this market is untapped and needs explorations, hence, the companies can get the benefit of first-mover advantage.

Results suggest that potential effects of energy transition support new risk-taking and risk acceptability to improve the energy mechanisms. It can be concluded that risk acceptability and tolerability can be adjusted up to 35 percent. The potential effects of energy transition can be positively used in mind-making and psychological pressure handling. Another element that has a prominent and deeper effect on risk acceptability and tolerability is related to government support. The study concluded that government support in Pakistan is enabling organizations to take risks in the energy sector as it is providing a friendly and lucrative environment for organizations for operations. The contribution of government support is healthy with a percentage of 27. However, another factor that is not supportive in risk acceptability and tolerability is effective measures. That indicates that the measures taken in the context of Pakistan are not matured enough to handle the energy risk and need more refinement and smoothness. Hence, it is concluded that the scale of risk acceptability and tolerability in the context of Pakistan is moderate, which encourages companies to work progressively and increase sociocultural activities to make society a partner of this new shift in energy transition that will ultimately increase the level of risk acceptability. Furthermore, addressing the main research question, the risk acceptability and tolerability level in the context of Pakistan is moderate. As a society, people are not high-risk takers neither risk avoiders due to limitation of income, uncertainty, and political instability. 


\section{Policy Recommendations}

Numerous recommendations can be suggested to researchers, practitioners, and policymakers based upon results and conclusions. As more people are willing to take the financial risk for energy transition the companies can make alliances with communities and can generate pools of funds to invest and operate. This act will increase the acceptability level of risk as communities are partners with these projects. According to the results, the government is supportive in increasing the level of risk acceptability, so it is recommended to companies to get a guarantee from the state in new projects' installation regarding compensation for any loss due to difference between demand and supply. The government assures the companies that their services will become marketable at any cost, otherwise, the state will pay the difference.

It is recommended for companies to provide alternate use of oil and gas utilities so that the energy transition barrier can effectively be solved and increase the level of risk acceptability and tolerability in the energy market. Moreover, the companies should use the latest technologies that have less wastage of resources with maximum output. For companies, it is suggested to take effective measures and use modern risk acceptability models such as ALARP for effectual operations. The companies should deeply study the meta-constitutional laws and activities in a contextual setting for sustainable operations. It is highly recommended to organizations to focus on agriculture R \& D also, as energy transition risk is associated with food shortage and squeezing of farming land, resulting in an alarming situation for wildlife and livestock.

\section{Conclusions}

To draw conclusions on present research and to narrate the hypothesis, the study has come up with numerous findings in accordance with discussion and results presented before. The findings significantly indicate that risk acceptability and tolerability in the context of Pakistan is an important phenomenon that companies need to address. Furthermore, it is indicated that risk should be measured in quantitative terms rather a qualitative term. It is evident from findings that government support to the organization to mitigate the risks associated with energy transitions is central for sustained operations. Results indicate that most of the people of Pakistan are willing to sacrifice their financials and are ready to take new risks of the energy transition. It is encouraging for companies to use their full potential to serve the energy market for the better future of Pakistan, specifically, and for a better future of the world, generally. However, the presence of literature on risk acceptability and tolerability is in dearth specifically in the context of Pakistan. However, the understanding of the connotation of risk acceptability at the industrial level is as better as to functionally the industry. In addition to gauging the readiness of people to take new risks of the energy transition, people with a huge number are willing to access the risk in quantitative terms in order to decide on a factual basis. It supports the situation by changing the energy production and consumption perspective from conventional to sustainable.

The essence of the sustainable energy transition is underpinned in renewable energy sources and is becoming the urge to future energy systems especially wind and solar energy. So, we have to check the conditions on which people are willing to adopt renewable energy sources. Meanwhile, we have to educate the individuals to make their understanding better. Other than that, enhancing the efficiency of the renewable energy system, the companies also have to focus on improving their production systems to reduce electricity consumption. Moreover, individuals can produce energy efficiently and can invest in solar energy sources as an easily available source. They also have to electrify the appliance that is energy efficient so that their energy demand can be reduced. They also have to change their daily behavior of using energy [73]. Additionally, it is noteworthy to clarify that the production of renewable energy is strongly correlated with environmental conditions, and in many parts of the world, it is not readily available, especially solar energy. Hence, people have to balance their energy consumption and energy production to get rid of any inconvenience. It can be benefited through new technology on both sides, consumption and production. 
They have to use autonomous switches to shift and manage electricity burdens. In addition, its people can use storage technologies such as batteries and electric vehicles.

The study has certain limitations. As it is narrowed down to specific organizations further, it can be extended to other industries as well who have potential effects on energy transition. The data sample is small; future researchers can increase the sample size along with adding more industries.

Author Contributions: Conceptualization, M.R. and A.A.; Formal analysis, S.M. and S.A.H.; Funding acquisition, M.S.; Investigation, M.R.; Resources, S.M.; Software, S.M.D.; Validation, S.A.H.; Visualization, S.N.; Writing-review \& editing, M.R. and A.A. All authors have read and agreed to the published version of the manuscript.

Funding: This research received no external funding.

Institutional Review Board Statement: Not applicable.

Informed Consent Statement: Not applicable.

Data Availability Statement: Not applicable.

Acknowledgments: The open access of this research is supported by the SPEV project 2021 at the Faculty of Informatics and Management, University of Hradec Kralove, Czech Republic.

Conflicts of Interest: The authors declare no conflict of interest.

\section{References}

1. Urbanik, M.; Tchórzewska-Cieślak, B.; Pietrucha-Urbanik, K. Analysis of the Safety of Functioning Gas Pipelines in Terms of the Occurrence of Failures. Energies 2019, 12, 3228. [CrossRef]

2. Tchiehe, D.N.; Gauthier, F. Classification of risk acceptability and risk tolerability factors in occupational health and safety. Saf. Sci. 2017, 92, 138-147. [CrossRef]

3. Sueyoshi, T.; Ryu, Y.; Yun, J.-Y. COVID-19 Response and Prospects of Clean/Sustainable Energy Transition in Industrial Nations: New Environmental Assessment. Energies 2021, 14, 1174. [CrossRef]

4. Thao, H.; Van Tiep, N.; Linh, D.T.T. Evaluating Risks in Construction Projects Based on International Risk management Standard AS/NZS ISO 31000: 2009. Infrastruct. Univ. Kuala Lumpur Res. J. 2014, 2, 38-50.

5. McComas, K.A.; Besley, J.C.; Yang, Z. Risky Business: Perceived Behavior of Local Scientists and Community Support for Their Research. Risk Anal. 2008, 28, 1539-1552. [CrossRef]

6. Vlek, C.; Stallen, P.-J. Rational and personal aspects of risk. Acta Psychol. 1980, 45, 273-300. [CrossRef]

7. Schönborn, G.; Berlin, C.; Pinzone, M.; Hanisch, C.; Georgoulias, K.; Lanz, M. Why social sustainability counts: The impact of corporate social sustainability culture on financial success. Sustain. Prod. Consum. 2019, 17, 1-10. [CrossRef]

8. Goštautaite, B.; Bučiūnienè, I. Work engagement during life-span: The role of interaction outside the organization and task significance. J. Vocat. Behav. 2015, 89, 109-119. [CrossRef]

9. Laplanche, G.; Gadaud, P.; Horst, O.; Otto, F.; Eggeler, G.; George, E. Temperature dependencies of the elastic moduli and thermal expansion coefficient of an equiatomic, single-phase CoCrFeMnNi high-entropy alloy. J. Alloy. Compd. 2015, 623, 348-353. [CrossRef]

10. Kulik, C.; Ryan, S.; Harper, S.; George, G. Aging Populations and Management. Acad. Manag. J. 2014, 57, 929-935. [CrossRef]

11. Pfeffer, J. Building sustainable organizations: The human factor. Acad. Manag. Perspect. 2010, 24, 34-45.

12. Hirsh, R.F.; Jones, C.F. History's contributions to energy research and policy. Energy Res. Soc. Sci. 2014, 1, 106-111. [CrossRef]

13. Stewart, M.G.; Netherton, M.D.; Rosowsky, D.V. Terrorism Risks and Blast Damage to Built Infrastructure. Nat. Hazards Rev. 2006, 7, 114-122. [CrossRef]

14. Patterson, G.R.; Reid, J.B.; Dishion, T.J. Antisocial Boys; Castalia Pub Co.: Eugene, OR, USA, 1992; Volume 4.

15. Skitka, L.J.; Bauman, C.W.; Lytle, B.L. Limits on legitimacy: Moral and religious convictions as constraints on deference to authority. J. Pers. Soc. Psychol. 2009, 97, 567-578. [CrossRef] [PubMed]

16. Schjølberg, I.; Østdahl, A.B. Security and tolerable risk for hydrogen service stations. Technol. Soc. 2008, 30, 64-70. [CrossRef]

17. Haridasan, R.; Kumar, M.; Marathe, P.P. Safety analysis of 2004 coincidence logic systems. Int. J. Syst. Assur. Eng. Manag. 2014, 6, 26-31. [CrossRef]

18. Finlay, P.; Fell, R.; Maguire, P. The relationship between the probability of landslide occurrence and rainfall. Can. Geotech. J. 1997, 34, 811-824. [CrossRef]

19. Schwartz, S.H. Universals in the Content and Structure of Values: Theoretical Advances and Empirical Tests in 20 Countries. Adv. Exp. Soc. Psychol. 1992, 25, 1-65. [CrossRef]

20. Steg, L.; Bolderdijk, J.W.; Keizer, K.; Perlaviciute, G. An Integrated Framework for Encouraging Pro-environmental Behaviour: The role of values, situational factors and goals. J. Environ. Psychol. 2014, 38, 104-115. [CrossRef] 
21. Chess, C.; Purcell, K. Public Participation and the Environment: Do We Know What Works? Environ. Sci. Technol. 1999, 33, 2685-2692. [CrossRef]

22. Huijts, N.M.A.; Molin, E.J.E.; Steg, L. Psychological factors influencing sustainable energy technology acceptance: A review-based comprehensive framework. Renew. Sustain. Energy Rev. 2012, 16, 525-531. [CrossRef]

23. Zoellner, J.; Schweizer-Ries, P.; Wemheuer, C. Public acceptance of renewable energies: Results from case studies in Germany. Energy Policy 2008, 36, 4136-4141. [CrossRef]

24. Smil, V. Examining energy transitions: A dozen insights based on performance. Energy Res. Soc. Sci. 2016, 22, 194-197. [CrossRef]

25. Markard, J.; Raven, R.; Truffer, B. Sustainability transitions: An emerging field of research and its prospects. Res. Policy 2012, 41, 955-967. [CrossRef]

26. Geels, F. Ontologies, socio-technical transitions (to sustainability), and the multi-level perspective. Res. Policy 2010, 39, 495-510. [CrossRef]

27. Geels, F.W. A socio-technical analysis of low-carbon transitions: Introducing the multi-level perspective into transport studies. J. Transp. Geogr. 2012, 24, 471-482. [CrossRef]

28. Geels, F.W.; Schot, J. Typology of sociotechnical transition pathways. Res. Policy 2007, 36, 399-417. [CrossRef]

29. Rafiq, M.; Zhang, X.; Yuan, J.; Naz, S.; Maqbool, S. Impact of a Balanced Scorecard as a Strategic Management System Tool to Improve Sustainable Development: Measuring the Mediation of Organizational Performance through PLS-Smart. Sustainability 2020, 12, 1365. [CrossRef]

30. Spaargaren, G.; Oosterveer, P.; Loeber, A. Food Practices in Transition: Changing Food Consumption, Retail and Production in the Age of Reflexive Modernity; Routledge: London, UK, 2013.

31. Lin, X.; Wells, P.; Sovacool, B.K. The death of a transport regime? The future of electric bicycles and transportation pathways for sustainable mobility in China. Technol. Forecast. Soc. Chang. 2018, 132, 255-267. [CrossRef]

32. Corner, A.; Whitmarsh, L.; Xenias, D. Uncertainty, scepticism and attitudes towards climate change: Biased assimilation and attitude polarisation. Clim. Chang. 2012, 114, 463-478. [CrossRef]

33. Ari, I.; Koksal, M.A. Carbon dioxide emission from the Turkish electricity sector and its mitigation options. Energy Policy 2011, 39, 6120-6135. [CrossRef]

34. IPCC Climate Change. The physical science basis. In Contribution of Working Group I to the Fourth Assessment Report of the Intergovernmental Panel on Climate Change; Cambridge University Press: Cambridge, UK; New York, NY, USA, 2007 ; Volume 996.

35. BMWi, B. Energiekonzept für eine Umweltschonende, Zuverlässige und Bezahlbare Energieversorgung, Federal Ministry of Economics and Technology (BMWi) Together with Federal Ministry for the Environment; Nature Conservation and Nuclear Safety (BMU): Berlin, Germany, 2010.

36. Richter, M. Business model innovation for sustainable energy: German utilities and renewable energy. Energy Policy 2013, 62, 1226-1237. [CrossRef]

37. Klose, C.; Khaire, T.S.; Wang, Y.; Pratt, W.P.; Birge, N.O.; McMorran, B.J.; Borchers, J.A.; Ginley, T.; Kirby, B.J.; Maranville, B.B.; et al. Correlation between spin-flop transition and enhanced spin polarized supercurrents in ferromagnetic Josephson junctions. Accompl. Oppor. 2012, 1500, 28.

38. Schleicher-Tappeser, R. How renewables will change electricity markets in the next five years. Energy Policy 2012, 48, 64-75. [CrossRef]

39. Small, F.; Frantzis, L. The 21st Century Electric Utility. Positioning for a Low-Carbon Future; Ceres Report: Boston, MA, USA, 2010.

40. Chang, S.-S.; Stuckler, D.; Yip, P.; Gunnell, D. Impact of 2008 global economic crisis on suicide: Time trend study in 54 countries. BMJ 2013, 347, f5239. [CrossRef] [PubMed]

41. Taylor, A.; Helfat, C.E. Organizational Linkages for Surviving Technological Change: Complementary Assets, Middle Management, and Ambidexterity. Organ. Sci. 2009, 20, 718-739. [CrossRef]

42. O'Reilly, C.A.; Tushman, M.L. The ambidextrous organization. Harv. Bus. Rev. 2004, 82, 74.

43. Miller, S.D.; Wampold, B.E. The Heart and Soul of Change: Delivering What Works in Therapy; Duncan, B.L., Hubble, M.A., Eds.; American Psychological Association: Washington, DC, USA, 2010.

44. Gupta, Y.; Metchop, L.; Frantzis, A.; Phelan, P. Comparative analysis of thermally activated, environmentally friendly cooling systems. Energy Convers. Manag. 2008, 49, 1091-1097. [CrossRef]

45. Nimmons, J.; Taylor, M. Utility solar business models. In Emerging Utility Strategies \& Innovation; Solar Electric Power Association (SEPA) Publication: Washington, DC, USA, 2008.

46. Chandler, T.J.; Brown, L.E. Conditioning for Strength and Human Performance, 2nd Edition. J. Can. Chiropr. Assoc. 2013, 57, 94.

47. Warr, B.; Ayres, R. Evidence of causality between the quantity and quality of energy consumption and economic growth. Energy 2010, 35, 1688-1693. [CrossRef]

48. Coll-Mayor, D.; Paget, M.; Lightner, E. Future intelligent power grids: Analysis of the vision in the European Union and the United States. Energy Policy 2007, 35, 2453-2465. [CrossRef]

49. Solomon, B.D.; Krishna, K. The coming sustainable energy transition: History, strategies, and outlook. Energy Policy 2011, 39, 7422-7431. [CrossRef]

50. Jacobsson, S.; Lauber, V. Transforming the energy system-the evolution of the German technological system for solar cells. Energy Policy 2006, 34, 256-275. [CrossRef] 
51. Ikenberry, G.J. The irony of state strength: Comparative responses to the oil shocks in the 1970s. Int. Organ. 1986, 40, 105-137. [CrossRef]

52. Barrett, J.; Peters, G.; Wiedmann, T.; Scott, K.; Lenzen, M.; Roelich, K.; Le Quéré, C. Consumption-based GHG emission accounting: A UK case study. Clim. Policy 2013, 13, 451-470. [CrossRef]

53. Fischer, C.; Newell, R.G. Environmental and technology policies for climate mitigation. J. Environ. Econ. Manag. 2008, 55, 142-162. [CrossRef]

54. Hovi, J.; Sprinz, D.F.; Underdal, A. Implementing Long-Term Climate Policy: Time Inconsistency, Domestic Politics, International Anarchy. Glob. Environ. Politi. 2009, 9, 20-39. [CrossRef]

55. Michaelowa, A.; Jotzo, F. Transaction costs, institutional rigidities and the size of the clean development mechanism. Energy Policy 2005, 33, 511-523. [CrossRef]

56. Gourevitch, P. The second image reversed: The international sources of domestic politics. Int. Organ. 1978, 32, 881-912. [CrossRef]

57. Katzenstein, P.J. Small States in World Markets: Industrial Policy in Europe; Cornell University Press: Ithaca, NY, USA, 1985.

58. Alesina, A.; Tabellini, G. A Positive Theory of Fiscal Deficits and Government Debt. Rev. Econ. Stud. 1990, 57, 403-414. [CrossRef]

59. Kline, D.; Vimmerstedt, L.; Benioff, R. Clean energy technology transfer: A review of programs under the UNFCCC. Mitig. Adapt. Strat. Glob. Chang. 2004, 9, 1-35. [CrossRef]

60. Laird, F.N.; Stefes, C. The diverging paths of German and United States policies for renewable energy: Sources of difference. Energy Policy 2009, 37, 2619-2629. [CrossRef]

61. Torvanger, A.; Meadowcroft, J. The political economy of technology support: Making decisions about carbon capture and storage and low carbon energy technologies. Glob. Environ. Chang. 2011, 21,303-312. [CrossRef]

62. Sovacool, B. What are we doing here? Analyzing fifteen years of energy scholarship and proposing a social science research agenda. Energy Res. Soc. Sci. 2014, 1, 1-29. [CrossRef]

63. Mercure, J.-F.; Pollitt, H.; Bassi, A.M.; Viñuales, J.E.; Edwards, N.R. Modelling complex systems of heterogeneous agents to better design sustainability transitions policy. Glob. Environ. Chang. 2016, 37, 102-115. [CrossRef]

64. Kariuki, D. Barriers to Renewable Energy Technologies Development; Keele University: Keele, UK, 2018. [CrossRef]

65. Alshehry, A.S.; Belloumi, M. Energy consumption, carbon dioxide emissions and economic growth: The case of Saudi Arabia. Renew. Sustain. Energy Rev. 2015, 41, 237-247. [CrossRef]

66. Eleftheriadis, I.M.; Anagnostopoulou, E.G. Identifying barriers in the diffusion of renewable energy sources. Energy Policy 2015, 80, 153-164. [CrossRef]

67. Bell, E.; Bryman, A.; Harley, B. Business Research Methods; Oxford University Press: Oxford, UK, 2018.

68. Gölz, S.; Wedderhoff, O. Explaining regional acceptance of the German energy transition by including trust in stakeholders and perception of fairness as socio-institutional factors. Energy Res. Soc. Sci. 2018, 43, 96-108. [CrossRef]

69. Henseler, J.; Ringle, C.M.; Sarstedt, M. A new criterion for assessing discriminant validity in variance-based structural equation modeling. J. Acad. Mark. Sci. 2015, 43, 115-135. [CrossRef]

70. Davis, L.L. Instrument review: Getting the most from a panel of experts. Appl. Nurs. Res. 1992, 5, 194-197. [CrossRef]

71. Tavakol, M.; Dennick, R. Making sense of Cronbach's alpha. Int. J. Med. Educ. 2011, 2, 53. [CrossRef] [PubMed]

72. Alarcón, D.; Sánchez, J.A.; de Olavide, U. Assessing convergent and discriminant validity in the ADHD-R IV rating scale: User-written commands for Average Variance Extracted (AVE), Composite Reliability (CR), and Heterotrait-Monotrait ratio of correlations (HTMT). In Proceedings of the Spanish STATA Meeting, Universidad Pablo de Olavide, Sevilla, Spain, 22 October 2015.

73. Faber, T.; Green, J.; Gual, M.; Haas, R.; Huber, C.; Resch, G.; Ruijgrok, W.; Twidell, J. Promotion Strategies for Electricity from Renewable Energy Sources in EU Countries. In Technology Report; Institute of Energy Economics Vienna University of Technologynstitute of Energy Economics, Vienna University of Technology: Vienna, Austria, 2001. 